\title{
Periphery-Functionalized Porous Organic Cages
}

\author{
Paul S. Reiss, ${ }^{[\mathrm{b}]}$ Marc A. Little ${ }^{[\mathrm{a}]}$ Valentina Santolini, ${ }^{[\mathrm{c}]}$ Samantha Y. Chong, ${ }^{[\mathrm{a}]}$ Tom Hasell, ${ }^{[\mathrm{a}]}$ Kim E. \\ Jelfs ${ }^{\left[{ }^{[c]}\right.}$ Michael E. Briggs ${ }^{*[a]}$ and Andrew I. Cooper ${ }^{*[a]}$
}

\begin{abstract}
By synthesizing derivatives of a trans-1,2 diaminocyclohexane precursor, three new functionalized porous organic cages were prepared with different chemical functionalities on the cage periphery. The introduction of twelve methyl groups (CC16) resulted in frustration of the cage packing mode, which more than doubled the surface area compared to the parent cage, CC3. The analogous installation of twelve hydroxyl groups provided an imine cage (CC17) that combines permanent porosity with the potential for post-synthetic modification of the cage exterior. Finally, the incorporation of bulky dihydroethanoanthracene groups was found to direct self-assembly towards the formation of a larger $[8+12]$ cage, rather than the expected [4+6], cage molecule (CC18). However, CC18 was found to be non-porous, most likely due to cage collapse upon desolvation.
\end{abstract}

\section{Introduction}

Porous organic cages (POCs) such as the imine cage $\mathbf{C C}^{[1]}$ (Scheme 1) have proved to be versatile functional materials. ${ }^{[2]}$ CC3 is formed by a cycloimination reaction between four molecules of triformylbenzene (TFB) and six molecules of homochiral trans-1,2-diaminocyclohexane (CHDA, 1). This molecule crystallizes with a window-to-window orientation that generates a 3-D diamondoid pore network that passes through the intrinsic cage voids. ${ }^{[3]}$ As a result of its simple, high-yielding synthesis, solution processability, and good physicochemical stability ${ }_{,}^{[4]} \mathbf{C C} 3$ has been used to form composite materials with enhanced separation properties: ${ }^{[5]}$ for example, for the separation of industrially relevant gas mixtures and chiral molecules. ${ }^{[6]}$ Other cage architectures based on boronate ester, ${ }^{[7]}$ boroxine,${ }^{[8]}$ and carbon-carbon ${ }^{[9]}$ bond formation have broadened the range of porous organic cage materials, and in some cases ${ }^{[10]}$ this has yielded materials with BrunauerEmmett-Teller (BET) surface areas that rival more established framework materials such as metal-organic frameworks (MOFs), covalent-organic frameworks (COFs), and amorphous polymer networks.

We first showed in 2009 how the surface functionality of a

\footnotetext{
[a] Dr. M. A. Little, Dr. S. Y. Chong, Dr. M. E. Briggs, Prof. A. I. Cooper Department of Chemistry and Materials Innovation Factory University of Liverpool

Crown Street, Liverpool, L69 7ZD, United Kingdom.

E-mail: mebriggs@liverpool.ac.uk and aicooper@liverpool.ac.uk

[b] Dr. P. S. Reiss

Green Chemistry Centre of Excellence

Department of Chemistry, University of York

Heslington, York, YO10 5DD, United Kingdom.

[c] V. Santolini, Dr. K. E. Jelfs

Department of Chemistry, Imperial College London

South Kensington, London, SW7 2AZ, United Kingdom.
}

Supporting information for this article is given via a link at the end of the document. series of isostructural imine cages could affect crystal packing and hence porosity. ${ }^{[1]}$ Until now, most variations on this theme within our group have involved commercially-available vicinal 1,2-diamines. ${ }^{[11]}$ An exception to this is our collaborative work with James and colleagues on porous liquids, ${ }^{[12]}$ which involved the synthesis of various ethylene diamine derivatives designed to decrease the melting point or increase the solubility of the resulting cages. More generally, the introduction of reactive functionality on the periphery of shape-persistent imine cages may expand their applications and allow new post-synthetic modification (PSM) strategies. For example, the attachment of ligands onto the cage periphery could be used to tune solubility, melting point, or crystal packing. Alternatively, cages with reactive external functional groups might be used as 'preporous' building blocks for extended MOFs or COFs. ${ }^{[13]}$ For imine POCs, most examples of PSM, so far, begin with the reduction of the imine bond to the more stable but flexible secondary amine, which is usually associated with the collapse of the pore structure upon desolvation. ${ }^{[14]}$ To our knowledge, the only example of PSM on a shape-persistent imine POC was reported by Schneider et al., who focused on the etherification of internal hydroxyl groups. ${ }^{[15]}$ This resulted in a decrease in accessible surface area due to occupation of the intrinsic cavity in the cage by alkyl chains. There is a need, therefore, to develop new diamine building blocks for POCs with richer external functionality.

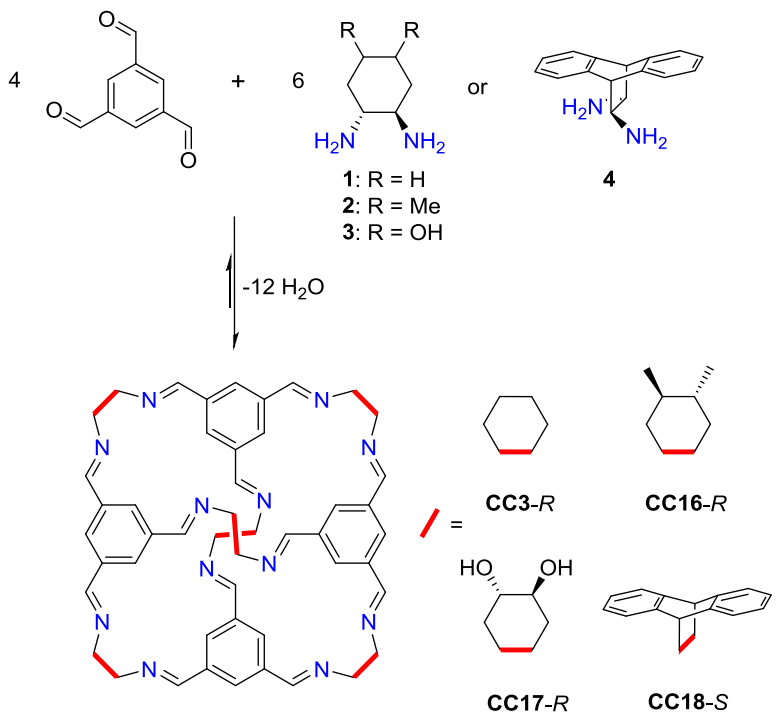

Scheme 1. Reaction scheme for the synthesis of cages CC16 and CC17. The $[4+6]$ isomer of $\mathbf{C C 1 8}$ was not isolated; instead, a larger [8+12] cage was formed (see below). 
a

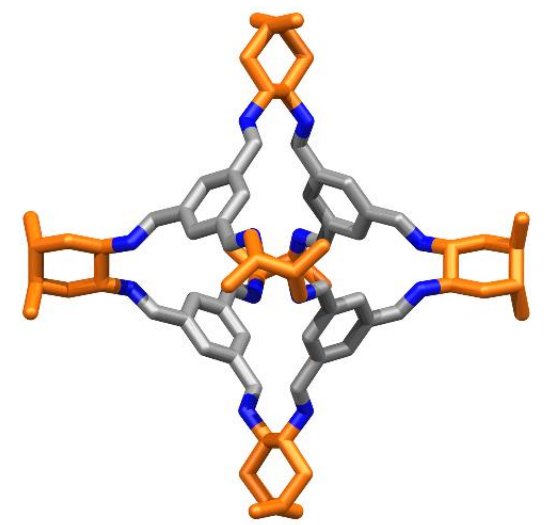

e

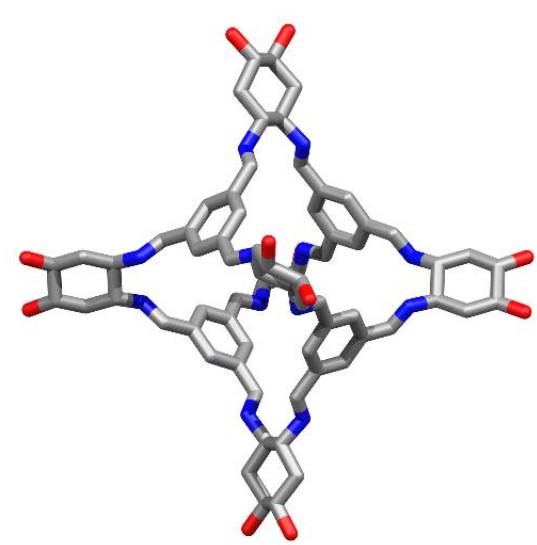

b

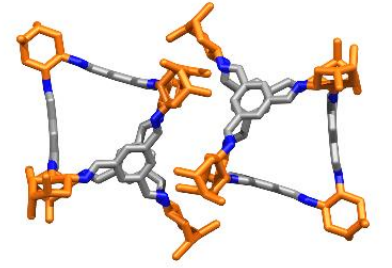

C

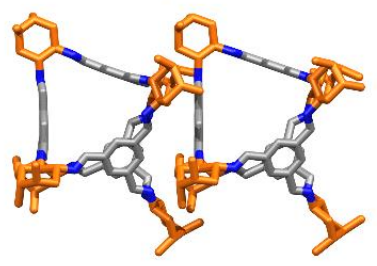

d

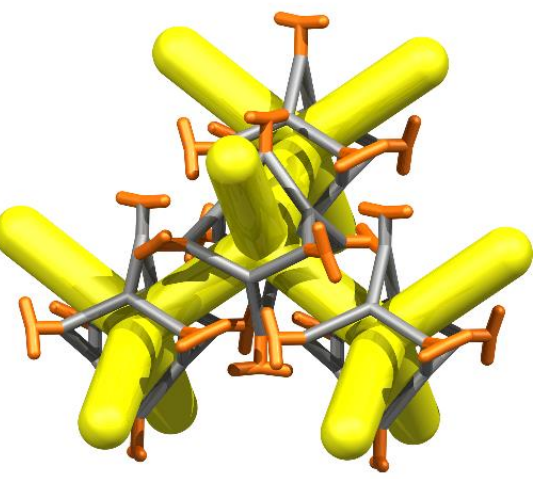

f

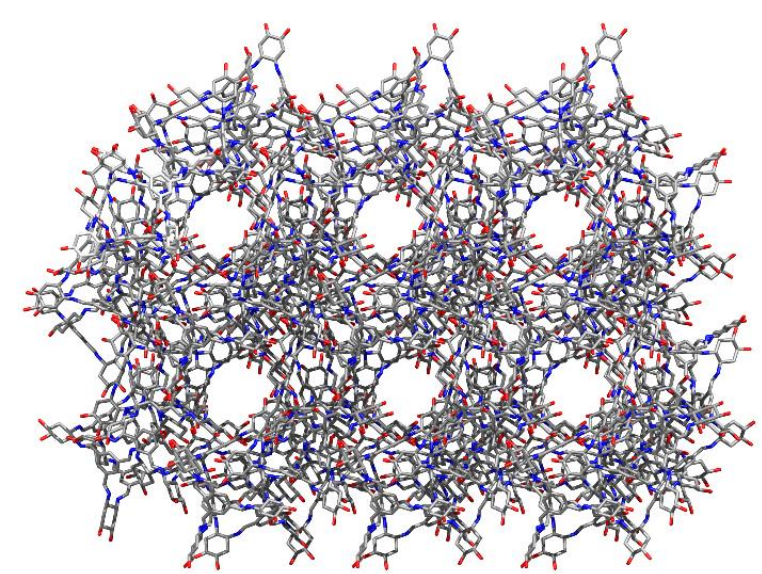

Figure 1. Molecular structure of Cc16-R (a). The cage is disordered over two positions and can pack window-to-window (b) or window-to-arene (c) in the crystal. A diamondoid pore network structure exists in crystalline $\mathbf{C C 1 6 - R}$ between the cages that are packed window-to-window (d). Molecular structure of CC17- $R$ (e). This cage crystallizes as a solvate (f) (solvent molecules omitted for clarity) that is not stable to removal of the solvent.

Three enantiomerically-pure vicinal 1,2-diamines derived from CHDA were selected as candidates for POC synthesis. (1R,2R,4R,5R)-4,5-Dimethylcyclohexane-1,2-diamine introduces twelve methyl groups onto the exterior of CC3 (Figure 1a). These methyl groups frustrate the cage packing but they are small enough to avoid penetration into the cavity of adjacent cages. This results in additional extrinsic porosity between cages. (1S,2S,4R,5R)-4,5-Diaminocyclohexane-1,2diol (3) yields a POC, CC17, which combines permanent porosity with the potential for PSM via functionalization of the twelve peripheral hydroxyl groups. The more bulky $(11 S, 12 S)$ 9,10-dihydro-9,10-ethanoanthracene-11,12-diamine (4) was selected to further frustrate the cage packing, and potentially to enhance extrinsic porosity even more than we observed for CC16. Surprisingly, however, this diamine formed a large [8+12] cage, $\mathbf{C C 1 8}$, rather than the targeted $[4+6]$ cage. This is the first example of an [8+12] cage being isolated using TFB as a precursor. CC18 is not stable to desolvation, and yields a nonporous amorphous solid, whereas crystalline CC16 is significantly more porous than its structural analogue, CC3.

\section{Results and Discussion}

Diamine 2 was isolated as the hydrochloric acid salt following reported procedures. ${ }^{[16]} \mathrm{A}$ solution of this hydrochloride salt and triethylamine in methanol was layered on top of a solution of TFB in $\mathrm{CH}_{2} \mathrm{Cl}_{2}$ and left standing at room temperature for 5 days. After this time, the homogeneous, green reaction mixture was slowly concentrated under vacuum $\left(<20^{\circ} \mathrm{C}\right)$ to remove the $\mathrm{CH}_{2} \mathrm{Cl}_{2}$ solvent and to induce the precipitation of a white solid from the remaining methanol. The chirally pure methylfunctionalized cage, CC16- $R$, was isolated by vacuum filtration in a $79 \%$ yield. Analysis by MALDI-TOF mass spectrometry gave a molecular ion peak with $m / z=1286$, which correlates to a [4+6] cage structure (Figure S14). Vial-in-vial crystallization of the cage from $\mathrm{CH}_{2} \mathrm{Cl}_{2}$-ethyl acetate gave octahedral crystals, which were characterized by single crystal $X$-ray diffraction (SCXRD). CC16- $R$ crystallized in the cubic space group $F 4_{1} 32$, where the cage is disordered over two positions, A $(74 \%$ occupancy) and B (26\% occupancy). 


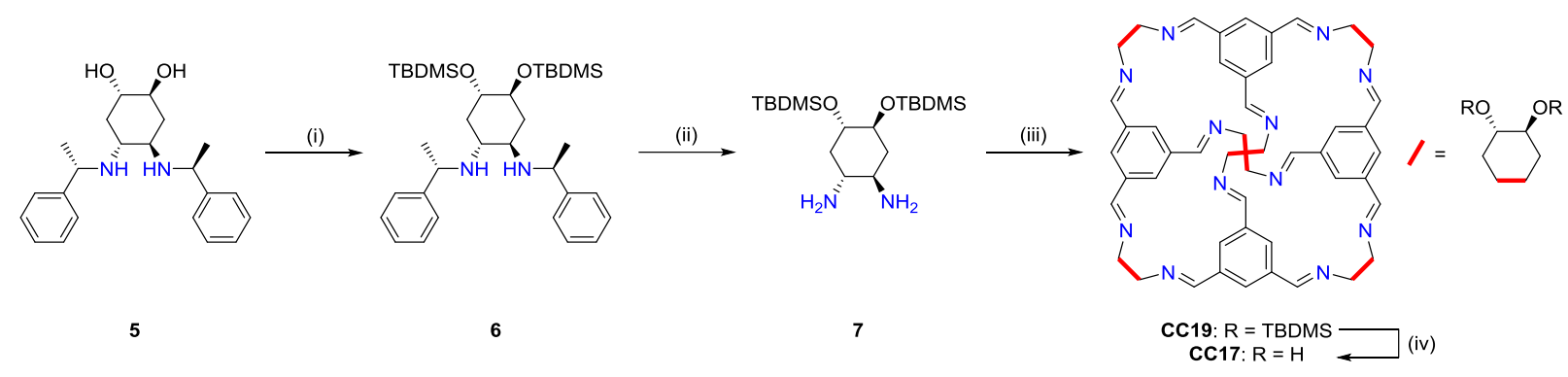

Scheme 2. Reaction scheme for the synthesis of CC17. Reaction conditions: (i) $\mathrm{TBDMSCl}$, imidazole, $\mathrm{CH}_{2} \mathrm{Cl}_{2}, \mathrm{rt}, 89 \%$. (ii) $\mathrm{Pd}(\mathrm{OH})_{2} / \mathrm{C}, \mathrm{H}_{2}, \mathrm{MeOH}, \mathrm{rt}$, $99 \%$. (iii) TFB, $\mathrm{CH}_{2} \mathrm{Cl}_{2}$, rt, $77 \%$. (iv) $1 \mathrm{M} \mathrm{TBAF}$, THF then $1 \mathrm{M}$ aq. $\mathrm{NH}_{4} \mathrm{Cl}, \mathrm{rt}, 61 \%$.

In position $\mathrm{A}$, the cages pack window-to-window (Figure $1 \mathrm{~b}+\mathrm{d}$ ) as observed for the parent cage, CC3, in its $\alpha$-phase..$^{[1]}$ In comparison with $\mathbf{C C 3}$, the peripheral methyl groups in $\mathbf{C C 1 6}$ frustrate the crystal packing and push the cages apart to create a $19 \%$ increase in the unit cell volume occupied by each cage molecule ( $1981 \AA^{3}$ vs. $2351 \AA^{3}$, respectively), which results in the generation of additional extrinsic porosity. However, unlike CC3, some structural disorder is observed in C.16, presumably as a result of the less compact packing, whereby $26 \%$ of cages occupy position B and pack window-to-arene (Figure 1c). These $B$ sites are randomly distributed through the crystal structure. As discussed below, this $26 \%$ of 'misaligned' cages does not prevent the material from being microporous. The desolvated bulk CC16 material, which was isolated by precipitation from methanol, was also found to be crystalline by powder X-ray diffraction (PXRD) analysis. The powder pattern closely matched the pattern simulated from the SCXRD analysis (Figure S17). Scanning electron microscope (SEM) images obtained for bulk and recrystallized samples also confirmed their crystalline nature, with both samples displaying octahedral crystal habits (Figure S19).

The incorporation of $(1 S, 2 S, 4 R, 5 R)$-4,5-diaminocyclohexane1,2-diol (3) into a POC is a desirable target because the peripheral hydroxyl groups offer scope for synthetic diversification by PSM. Diamine $\mathbf{3}$ was isolated as the hydrochloric acid salt following a literature procedure. ${ }^{[17]}$ We screened a range of conditions for the cage formation and found that the reaction of the hydrochloride salt with TFB typically resulted in the formation of an insoluble precipitate, probably comprising oligomeric by-products. However, using 100\% methanol as the reaction solvent appeared to slow the onset of precipitation, and after 4 days this afforded a mostly amorphous solid with small crystals embedded in it. Structure solution for these crystals by SCXRD showed that the desired [4+6] cage was present in the reaction mixture. The hydroxyl-functionalized cage, CC17- $R$, crystallized in the chiral tetragonal space group $P_{4} 2_{1} 2$ as a highly solvated material containing both methanol and water molecules (Figure 1f). The solvent volume of the reaction mixture was reduced under vacuum $\left(<20^{\circ} \mathrm{C}\right)$ and the bulk solid isolated by vacuum filtration. High-performance liquid chromatography (HPLC) analysis showed the reaction mixture to contain both cage and oligomeric by-products (Figure S20). Pure $\mathbf{C C 1 7}$ could be isolated as an amorphous white solid by preparative HPLC, although the overall yield was poor (17\%). Analysis by MALDI-TOF mass spectrometry gave a molecular ion peak with $m / z=1310$, which correlates with the [4+6] cage observed by SCXRD (Figure S15). The low reaction yield is thought to be due to the poor solubility of kinetic intermediates, which precipitate before equilibrating to the desired cage product. To improve solubility, it was decided to use diamine $\mathbf{7}$, where the diols are protected, to form the cage before deprotecting to afford the hydroxyl-decorated cage. tertButyldimethylsilyl chloride (TBDMSCI) was identified as a suitable protecting agent because it preferentially reacts with alcohols over secondary amines and it is stable to the hydrogenation conditions required to remove the chiral auxiliary. ${ }^{[18]}$ The reaction of the ethylbenzyl-protected diol diamine $\mathbf{5}$ with TBDMSCl in the presence of imidazole as a catalyst led to 6 in $89 \%$ isolated yield after purification by flash column chromatography. ${ }^{[19]}$ The free diamine was generated via hydrogenation and then reacted with TFB in $\mathrm{CH}_{2} \mathrm{Cl}_{2}$ (Scheme 2). After 7 days, a white precipitate was formed. To maximise the yield, the volume of solvent was first reduced under vacuum $\left(<20{ }^{\circ} \mathrm{C}\right)$ and the solid was isolated by vacuum filtration to afford amorphous $\mathbf{C C 1 9}$ in $77 \%$ yield. Analysis by ${ }^{1} \mathrm{H}$ NMR spectroscopy (Figure S6) showed that the TBDMS protecting group was retained in the final cage product. Analysis by MALDI-TOF mass spectrometry gave a molecular ion peak with $\mathrm{m} / \mathrm{z}=2680$, which correlates to the expected [4+6] cage structure (Figure S16). The hydroxyl groups were then regenerated by treatment with tetrabutylammonium fluoride (TBAF). ${ }^{[20]}$ Isolation of the pure cage proved difficult: purification of the crude reaction product by preparative HPLC was unsuccessful, with impure material being isolated on each attempt. The cage could be successfully recovered from the aqueous suspension obtained after the work-up of the reaction mixture using a centrifuge filter, followed by washing with wateracetonitrile (95:5) and then with water. CC17 was finally isolated from the aqueous suspension in $61 \%$ yield by 

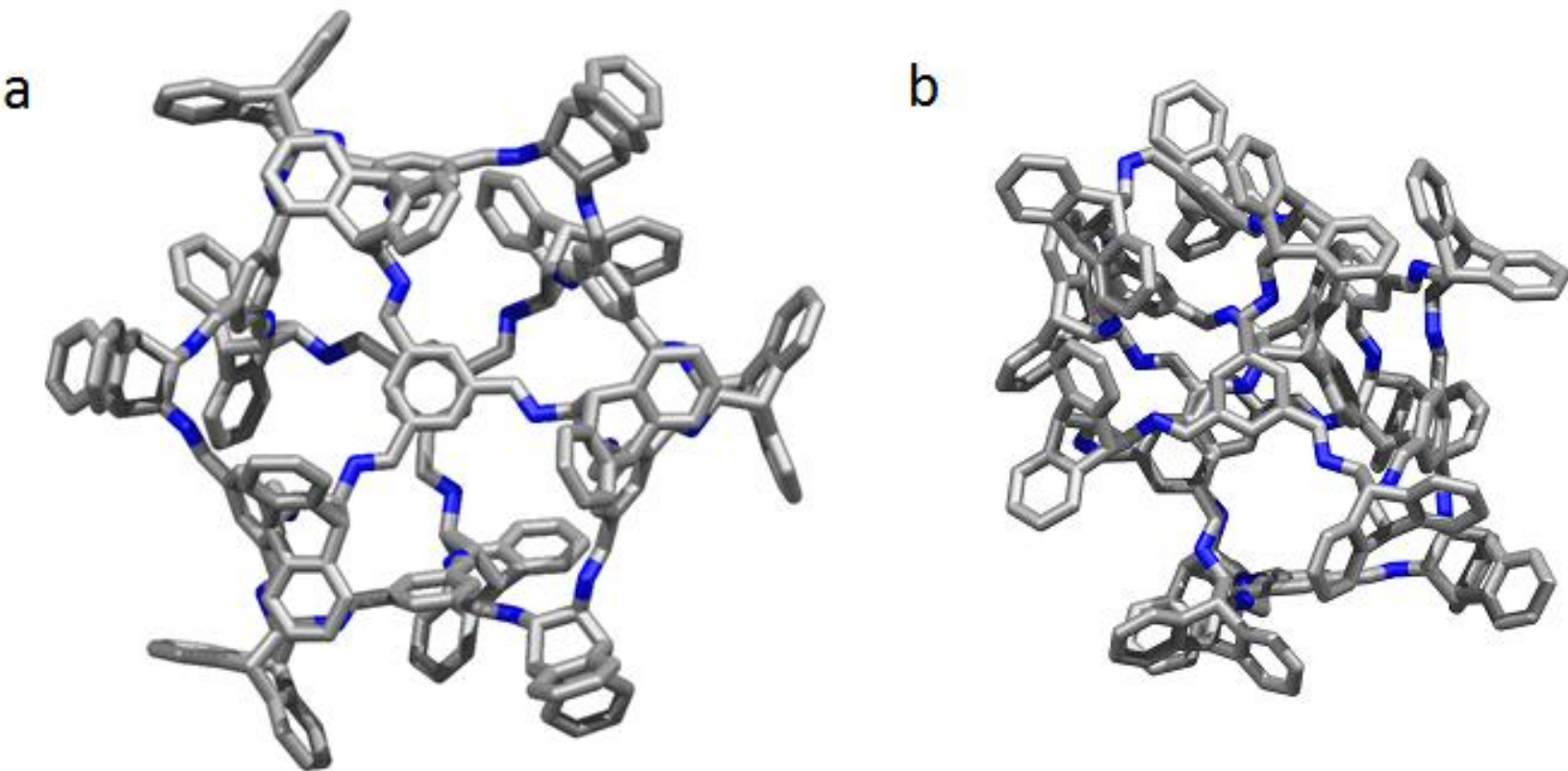

Figure 2. Solvated CC18-S (crystal structure, solvent molecules removed for clarity) (a) that collapses on desolvation (b) (grey, carbon; blue, nitrogen; protons omitted for clarity).

freeze-drying. Analysis by ${ }^{1} \mathrm{H}$ NMR spectroscopy showed it was the same material isolated via the initial, lower yielding route (Figure S4). This demonstrates that the imine cage structure is stable towards basic TBAF. PXRD analysis of the freeze-dried sample showed it to be amorphous. Single crystals could be isolated from several solvent systems, including trifluoroethanoltetrahydrofuran (THF) and dimethylformamide-acetone. However, attempts to desolvate $\mathbf{C C 1 7}$ through gentle heating led to a loss of crystallinity in all cases.

Inspired by the effect that the peripheral methyl groups had on the extrinsic porosity in CC16, we also explored bulky diamine 4 . Reactions between TFB and $\mathbf{4}$ in $\mathrm{CH}_{2} \mathrm{Cl}_{2}$ resulted in consumption of the aldehyde and a mixture of imine products. The reaction equilibrium could be shifted towards a single product by adding a catalytic amount of trifluoroacetic acid (TFA). Although other species were still observable under these conditions, they were less prominent and could be removed by swapping the reaction solvent to acetone, in which these impurities (but not the main cage product) were soluble. CC18 precipitated as a white solid and was isolated in $32 \%$ yield. Analysis by ${ }^{1} \mathrm{H}$ NMR spectroscopy confirmed the purity of the cage, with sharp singlets at $\delta 8.28 \mathrm{ppm}$ and $\delta 7.80 \mathrm{ppm}$ confirming the presence of imine and aromatic protons, respectively, in a 1:1 ratio (Figure S5). In addition, the two singlets at $\delta 4.09 \mathrm{ppm}$ and $\delta 3.75 \mathrm{ppm}$ could be assigned to the protons at the bridgehead positions. Analysis by MALDI-TOF mass spectrometry was inconclusive, with only very weak molecular ion peaks being observed. The bulk CC18 product was isolated initially as an amorphous solid, as confirmed by PXRD analysis. However, vial-in-vial crystallization of the cage from $\mathrm{CH}_{2} \mathrm{Cl}_{2}$-acetone gave needle-like crystals that were solved by SCXRD. CC18-S crystallized in the chiral trigonal space group $P 321$ as an [8+12] cage (Figure 2). CC18 is the first
[8+12] imine cage to be prepared using TFB as a precursor. This may be due to a subtle change in the bond angles of the diamine, 4 . To probe this, the relative energies of the theoretical $[4+6]$ cage and the observed [8+12] cage were examined using gas-phase Density Functional Theory (DFT) calculations. While these calculations do not take into account any solvation effects, the results showed that the larger [8+12] cage was energetically favoured by $10 \mathrm{~kJ} \mathrm{~mol}^{-1}$ per [4+6] unit. Imine cages with an $[8+12]$ stoichiometry are rare and none has yet proven to be shape-persistent enough to remain porous in the desolvated solid state. ${ }^{[21]}$ This is a result of the increased flexibility of larger cages and the cumulative effect of the increased number of rotatable bonds. Molecular dynamics (MD) simulations for CC18-S, in the absence of solvent, showed that a collapsed cage conformation (Figure 2b) is $65 \mathrm{~kJ} \mathrm{~mol}^{-1}$ lower in energy than the open conformer found in the solvate. In keeping with this, the crystalline CC18-S solvate quickly became amorphous when left in air, presumably due to structural rearrangement of the cage upon solvent loss (Figure S18).

Nitrogen sorption measurements for $\mathbf{C C} 16$ at $77 \mathrm{~K}$ and 1 bar showed a Type I isotherm with a total gas uptake of $20.03 \mathrm{mmol} \mathrm{g}^{-1}$ and an apparent BET surface area of $1023 \mathrm{~m}^{2} \mathrm{~g}^{-1}$; that is, more than double the surface area observed for highly crystalline CC3 (Table 1). ${ }^{[3]}$ The increase in surface area and overall $\mathrm{N}_{2}$ and $\mathrm{H}_{2}$ uptakes for $\mathrm{CC} 16$ is a consequence of the peripheral methyl groups, which generate extra accessible space between the cage molecules. 
Table 1. Gas sorption values recorded at 1 bar for $\mathbf{C C} 3$ and enantiomericallypure CC16-CC18.

\begin{tabular}{ccccc}
\hline & $\begin{array}{c}S A_{\mathrm{BET}} / \\
\mathrm{m}^{2} \mathrm{~g}^{-1}\end{array}$ & $\begin{array}{c}\mathrm{N}_{2} / \\
\mathrm{mmol} \mathrm{g}^{-1}\end{array}$ & $\begin{array}{c}\mathrm{H}_{2} / \\
\mathrm{mmol} \mathrm{g}^{-1}\end{array}$ & $\begin{array}{c}\mathrm{CO}_{2} / \\
\mathrm{mmol} \mathrm{g}^{-1}\end{array}$ \\
\hline $\mathbf{C C 3}{ }^{[3]}$ & 409 & $77 \mathrm{~K}$ & $77 \mathrm{~K}$ & $273 \mathrm{~K}$ \\
$\mathbf{C C 1 6}$ & 1023 & 20.03 & 5.90 & 2.01 \\
$\mathbf{C C 1 7}$ & 423 & 7.06 & 4.15 & 2.00 \\
$\mathbf{C C 1 8}$ & 10 & 0.45 & 2.61 & 1.81 \\
\hline
\end{tabular}

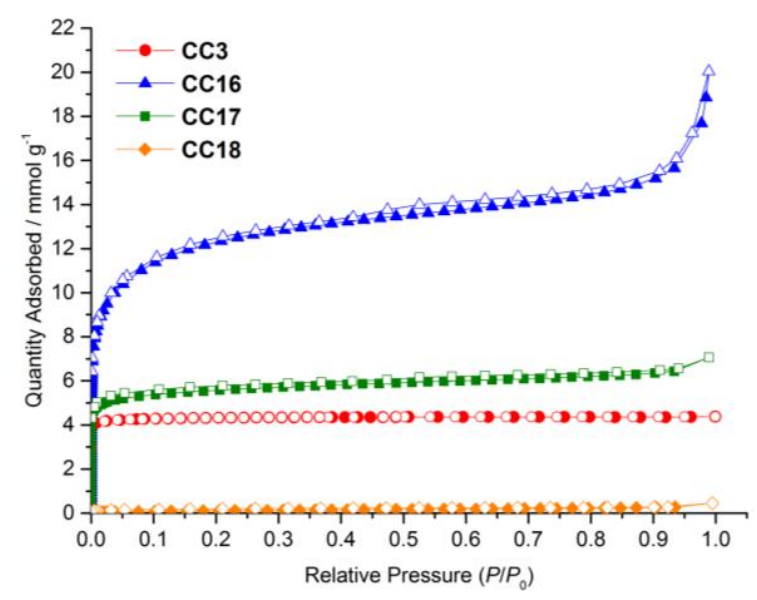

Figure 3. $\mathrm{N}_{2}$ adsorption isotherms for $\mathbf{C C 3}$ and enantiomerically-pure $\mathbf{C C 1 6}$ CC18 at $77 \mathrm{~K}$ and 1 bar. Adsorption and desorption isotherms are represented by closed and open symbols, respectively.

Previously, Schneider et al. investigated the influence of peripheral groups on the porosity of POCs by incorporating salicyldialdehydes with a range of substituents at the 4position. ${ }^{[22]}$ They found that bulkiness in the peripheral groups can be neglected when the POCs are amorphous because the porosity is dictated by the size of the intrinsic cavity within the cage. However, in the crystalline state, more stericallydemanding peripheral substituents imparted a lower accessible surface area. Despite becoming amorphous upon desolvation, hydroxyl-substituted CC17 displayed a total $\mathrm{N}_{2}$ uptake of $7.06 \mathrm{mmol} \mathrm{g}^{-1}$ and an apparent BET surface area of $423 \mathrm{~m}^{2} \mathrm{~g}^{-1}$ (Table 1). This surface area is lower than for amorphous CC3. ${ }^{[3]}$ This could be a consequence of hydrogen bonding between the hydroxyl groups, which may promote a denser packing, rather than generating additional extrinsic porosity. CC17 adsorbs less $\mathrm{CO}_{2}$ than $\mathbf{C C}$, even though the polar hydroxyl groups might be expected to promote the adsorption of acidic $\mathrm{CO}_{2}$ molecules, as demonstrated previously by Schneider et al., who showed that capping interior hydroxyl groups with methyl groups resulted in a reduction in $\mathrm{CO}_{2}$ uptake in their cage material. ${ }^{[15]}$ For $\mathbf{C C} 17$, it is possible that $\mathrm{CO}_{2}$ cannot gain access to the polar groups. Nitrogen sorption measurements for $\mathbf{C C 1 8}$ at $77 \mathrm{~K}$ and 1 bar mirrored the findings for other large imine cages: it was non- porous to $\mathrm{N}_{2}$, consistent with the collapse of the cage structure upon desolvation (Figure 3). However, CC18 did adsorb small amounts of $\mathrm{H}_{2}$ and $\mathrm{CO}_{2}$, indicating that the sterically-demanding dihydroethanoanthracene vertices may generate extrinsic pores of appropriate size to allow the adsorption of smaller gas molecules.

\section{Conclusions}

Enantiomerically-pure analogues of the POC precursor CHDA were prepared and reacted with TFB to synthesise three new cage molecules. CC16 was isolated as a phase-pure [4+6] cage, and the introduction of methyl groups onto the cage surface resulted in frustrated packing and higher porosity. By contrast, the incorporation of bulky dihydroethanoanthracene functionality led to the [8+12] cage, $\mathbf{C C 1 8}$, which is one of the largest imine cages prepared to date, although subsequent desolvation led to cage collapse. The peripheral hydroxyl groups in $\mathbf{C C 1 7}$ provide an imine cage that is amenable to further modification, for example, to tune properties such as solubility or melting point. Moreover, this tetrahedral cage, which has twelve symmetrically disposed hydroxyl groups on its periphery, might be a promising 'porous organic ligand' for the preparation of metal-organic or covalent organic frameworks. ${ }^{[13 a]}$

\section{Experimental Section}

\section{General}

Solution ${ }^{1} \mathrm{H}$ and ${ }^{13} \mathrm{C}$ NMR spectra were recorded at $400.13 \mathrm{MHz}$ and 100.6 MHz respectively using a Bruker Avance 400 NMR spectrometer. Chemical shifts are reported in ppm $(\delta)$ with reference to the internal residual protonated species of the deuterated solvent used for ${ }^{1} \mathrm{H}$ and ${ }^{13} \mathrm{C}$ analysis.

IR spectra were recorded using a Bruker Tensor 27 FT-IR spectrometer with Quest ATR (diamond crystal puck) attachment running Opus 6.5 software. Samples were analysed as dry powders for 16 scans with a resolution of $4 \mathrm{~cm}^{-1}$. Spectra were recorded in transmission mode.

$\mathrm{Cl}$ mass spectra were recorded using an Agilent Q-TOF 7201. ESI mass spectra were recorded using a Micromass LCT-MS. MALDI-TOF MS was conducted using an AXIMA Confidence MALDI MS (Shimadzu Biotech) fitted with a $50 \mathrm{~Hz} \mathrm{~N}$ laser. A 10:1 ratio of matrix/sample was dissolved in THF $\left(10 \mathrm{mg} \mathrm{mL}^{-1}\right)$ and this was drop coated onto the microtitre plate before analysis. For $\mathbf{C C 1 6}$, the matrix used was dithranol. For CC17 and CC19, the matrix used was trans-2-[3-(4-tert-butylphenyl)2-methyl-2-propenylidene]malononitrile (DCTB).

$\mathrm{CHN}$ analysis was conducted using a Thermo FlashEA 1112 Elemental Analyser. Samples were analysed as dry powders and the data was processed using dedicated elemental analysis software.

PXRD data for enantiomerically-pure CC16 were collected using a PANalytical X'Pert PRO HTS X-ray diffractometer with $\mathrm{Cu}-K \alpha_{1}$ radiation Samples were ground and mounted as a loose powder onto transparent film, with data collected in the range $4^{\circ} \leq 2 \theta \leq 50^{\circ}$ with a step size of $0.013^{\circ}$ over 1 hour.

For enantiomerically-pure $\mathbf{C C} \mathbf{1 8}$, as the cage was potentially sensitive to guest loss, crystals were ground and dispersed in a minimal volume of crystallization solvent before loading into borosilicate glass capillaries. Laboratory PXRD data were collected from the samples in transmission 
geometry on a PANalytical Empyrean diffractometer producing $\mathrm{Cu}-K \alpha_{1}$ radiation and equipped with an X-ray focussing mirror, using a PIXcel3D detector operating in 1-D scanning mode. Powder data were collected in the range $2^{\circ} \leq 2 \theta \leq 40^{\circ}$ in steps of $0.013^{\circ}$ over 1 hour. This program was cycled to monitor any structural changes over a period of 4 hours. In the absence of significant changes in diffraction, individual patterns were summed to generate a cumulative profile with improved counting statistics. The temperature of the capillary was controlled using an Oxford Cryosystems 700 Series Cryostream Plus.

High resolution imaging of the crystal morphology of CC16 was achieved using a Hitachi S-4800 Cold Field Emission Scanning Electron Microscope (FE-SEM). Scanning-mode samples were prepared by depositing dry crystals on $15 \mathrm{~mm}$ Hitachi M4 aluminium stubs using an adhesive high-purity carbon tab before coating with a $2 \mathrm{~nm}$ layer of gold using an Emitech K550X automated sputter coater. Imaging was conducted at a working distance of $8 \mathrm{~mm}$ and a working voltage of $3 \mathrm{kV}$ using a mix of upper and lower secondary electron detectors. The FESEM measurement scale bar was calibrated using certified SIRA calibration standards.

Analytical HPLC was conducted using a Dionex Ultimate 3000 HPLC system. The column used for the analysis of both crude and purified product samples of $\mathrm{CC}_{17}$ was Syncronis $\mathrm{C}_{8}, 150 \times 4.6 \mathrm{~mm}, 3 \mu \mathrm{m}(\mathrm{SN}$ 10136940, Lot 12459). The mobile phase was methanol-water (10:90 to 90:10 over 27 minutes) at a flow rate of $0.5 \mathrm{~mL} \mathrm{~min}^{-1}$. The injection volume was $2 \mu \mathrm{L}$ and the sample concentration was ca. $1 \mathrm{mg} \mathrm{mL}^{-1}$ in dimethylsulfoxide (DMSO). The column oven temperature was set to $30^{\circ} \mathrm{C}$. Detection for HPLC analysis was conducted at $254 \mathrm{~nm}$.

Preparative HPLC was conducted using a Shimadzu Prominence Preparative HPLC system. The column used for the purification of crude product samples of CC17 was Syncronis $\mathrm{C}_{8}, 150 \times 30 \mathrm{~mm}, 5 \mu \mathrm{m}$ (SN 10159851, Lot 12105). The mobile phase was methanol-water (10:90 to 90:10 over 9 minutes) at a flow rate of $35 \mathrm{~mL} \mathrm{~min}^{-1}$. The injection volume was $600 \mu \mathrm{L}$ and the sample concentration was ca. $20 \mathrm{mg} \mathrm{mL}^{-1}$ in DMSOmethanol $(2: 1)$. The column oven temperature was set to $30{ }^{\circ} \mathrm{C}$. Detection for HPLC analysis was conducted at $254 \mathrm{~nm}$

Single crystal X-ray data for CC16- $R$ was measured at beamline I19, Diamond Light Source, Didcot, UK using silicon double crystal monochromated synchrotron radiation $(\lambda=0.6889 \AA$, Rigaku Saturn724+ detector) $:{ }^{[23]}$ for CC17- $R$ on a Bruker D8 Venture Advance diffractometer equipped with $\mathrm{I} \mu \mathrm{S}$ microfocus source $(\mathrm{Cu}-\mathrm{K} \alpha$ radiation, $\lambda=1.54178 \AA$, Kappa 4-circle goniometer, PHOTON100 CMOS detector); and for CC18-S at beamline 11.3.1, Advanced Light Source, Berkeley, USA using silicon monochromated synchrotron radiation $(\lambda=0.7749 \AA$, PHOTON100 CMOS detector). Solvated single crystals, isolated from the crystallization solvent, were immersed in a protective oil, mounted on a MiTeGen loop, and flash cooled under a dry nitrogen gas flow. Empirical absorption corrections, using the multi-scan method, were performed with the program SADABS. ${ }^{[24]}$ Structures were solved with SHELXD, ${ }^{[25]}$ SHELXT, ${ }^{[26]}$ or by direct methods using SHELXS, ${ }^{[27]}$ and reined by fullmatrix least squares on $\mid F^{2}$ by SHELXL, ${ }^{[28]}$ interfaced through OLEX2. ${ }^{[29]}$ Supplementary CIFs, that include structure factors, have been deposited with The Cambridge Crystallographic Data Centre as entries 1481844 (CC16), 1481845 (CC17), and 1481846 (CC18). These files are available free of charge via www.ccdc.cam.ac.uk/data_request/cif.

The [4+6] versus [8+12] molecular mass of $\mathbf{C C 1 8}$ was initially evaluated using high temperature MD simulations in order to explore the potential energy surfaces and to identify the lowest energy conformers. MD simulations were performed with the Macromodel Software (Schrödinger PLC) and the recently released OPLS3 force field. ${ }^{[30]}$ The calculations were run at $1000 \mathrm{~K}$ for $100 \mathrm{~ns}$ with a time step of $1 \mathrm{fs}$, and each involved the sampling of 10,000 structures that were geometry optimized at each step of the simulation. Both open and collapsed conformers for $[4+6]$ and $[8+12]$ were re-optimized with DFT methods in order to rank the structures according to their energy with more accurate methods and therefore to predict the most likely reaction outcome. The four structures were optimized with the CP2K software ${ }^{[31]}$ using the $\mathrm{PBE}$ DFT functional, combined with a TZVP-MOLOPT basis set ${ }^{[32]}$ in combination with Geodecker-Teter-Hutter pseudopotentials, a planewave cut-off of $350 \mathrm{Ry}$, and Grimme's D3 dispersion correction. ${ }^{[33]}$

Surface areas for enantiomerically-pure CC16-CC18 were measured by $\mathrm{N}_{2}$ sorption at $77 \mathrm{~K}$ and 1 bar. Powder samples were degassed offline at $373 \mathrm{~K}$ for 15 hours under dynamic vacuum $\left(10^{-5}\right.$ bar) before analysis, followed by degassing on the analysis port under vacuum, also at $373 \mathrm{~K}$ Isotherms were measured using Micromeritics 2020 or 2420 volumetric adsorption analysers. $\mathrm{N}_{2}$ and $\mathrm{H}_{2}$ isotherms were maintained at $77 \mathrm{~K}$ by liquid nitrogen cooling. Higher temperature isotherms for $\mathrm{CO}_{2}(273 \mathrm{~K})$ required a circulating water chiller/heater to maintain the temperature. All measurements were carried out using high purity gases: $\mathrm{N}_{2}$ (N5.0: 99.999\% - BOC gases); $\mathrm{H}_{2}$ and $\mathrm{CO}_{2}$ (N5.5: 99.9995\% - BOC gases).

$\mathbf{2}^{\left[{ }^{[16]}\right.} \mathbf{3}$, and $\mathbf{5}^{[17]}$ were synthesized according to previously reported procedures. 4, 20\% palladium hydroxide on carbon and tertbutyldimethylsilyl chloride were purchased from TCI-UK. TFA was purchased from Alfa Aesar. TFB was purchased from Manchester Organics. Triethylamine was purchased from Alfa Aesar and distilled prior to use. All other reagents were purchased from Sigma Aldrich and all reagents, with the exception of triethylamine, were used as received. Hydrogen gas (99.995\% minimum; L05410A) was supplied by BOC gases.

\section{Synthetic Procedures}

(1R,2R,4S,5S)-4,5-Bis((tert-butyldimethylsilyl)oxy)-N,N'-bis((S)-1phenylethyl)cyclohexane-1,2-diamine (6): $:^{[19]} \mathrm{A}$ solution of tertbutyldimethylsilyl chloride $(0.86 \mathrm{~g}, 5.71 \mathrm{mmol})$ in $\mathrm{CH}_{2} \mathrm{Cl}_{2}(2 \mathrm{~mL})$ was added to a cooled solution of $5(0.81 \mathrm{~g}, 2.28 \mathrm{mmol})$ and imidazole $(0.39 \mathrm{~g}, 5.73 \mathrm{mmol})$ in $\mathrm{CH}_{2} \mathrm{Cl}_{2}(6 \mathrm{~mL})$. The reaction mixture was stirred at it for $16 \mathrm{~h}$. After this time, water $(8 \mathrm{~mL})$ was added. The organic phase was isolated and the aqueous phase extracted with $\mathrm{CH}_{2} \mathrm{Cl}_{2}(3 \times 15 \mathrm{~mL})$ The organic phases were combined and washed with water $(15 \mathrm{~mL})$ and a saturated solution of sodium hydrogen carbonate $(15 \mathrm{~mL})$, dried over anhydrous magnesium sulfate, filtered, and the filtrate concentrated to dryness under vacuum to afford the crude product as a white solid. This was purified by column chromatography (hexane-ethyl acetate, 93:7 to 50:50) to yield 6 as a white solid (1.18 g, $2.02 \mathrm{mmol}, 89 \%)$. ${ }^{1} \mathrm{H}$ NMR (400 $\left.\mathrm{MHz}, \mathrm{CDCl}_{3},\right) \delta=7.34-7.21(\mathrm{~m}, 10 \mathrm{H}, 10 \times \mathrm{ArH}), 3.80(\mathrm{q}, 2 \mathrm{H}, 2 \times \mathrm{Ph}-$ $\mathrm{CH}), 3.19(\mathrm{~m}, 2 \mathrm{H}, 2 \times \mathrm{CH}-\mathrm{O}), 2.09\left(\mathrm{~m}, 2 \mathrm{H}, 1 \times \mathrm{CH}_{2}\right), 1.95(\mathrm{~m}, 2 \mathrm{H}, 2 \times$ $\mathrm{CH}-\mathrm{NH}), 1.33\left(\mathrm{~d}, 6 \mathrm{H}, 2 \times \mathrm{CH}_{3}\right), 0.91\left(\mathrm{~m}, 2 \mathrm{H}, 1 \times \mathrm{CH}_{2}\right), 0.85(\mathrm{~s}, 18 \mathrm{H}, 6 \times$ $\left.\mathrm{CH}_{3}\right), 0.01\left(\mathrm{~s}, 6 \mathrm{H}, 2 \times \mathrm{CH}_{3}\right), 0.00\left(\mathrm{~s}, 6 \mathrm{H}, 2 \times \mathrm{CH}_{3}\right) ;{ }^{13} \mathrm{C}$ NMR $(100.6$ $\left.\mathrm{MHz}, \mathrm{CDCl}_{3}\right) \delta=145.6,128.6,127.1,126.8,74.2,55.7,54.9,37.7,26.2$, $25.4,18.2,-3.9,-4.6$; FT-IR (neat): $\tilde{v}=2956,2927,2853,1461,1360$, 1251, 1099, 1063, 1055, $923 \mathrm{~cm}^{-1}$; MS (Cl): $\mathrm{m} / \mathrm{z}: 583[\mathrm{M}+\mathrm{H}]^{+}$.

(1R,2R,4S,5S)-4,5-Bis((tert-butyldimethylsilyl)oxy)cyclohexane-1,2diamine (7): To an autoclave under a nitrogen atmosphere was added $20 \%$ palladium hydroxide on carbon $(0.81 \mathrm{~g}), 6(2.00 \mathrm{~g}, 3.43 \mathrm{mmol})$ and methanol $(145 \mathrm{~mL})$. The reaction mixture was stirred vigorously at $\mathrm{rt}$ under hydrogen at 10 atmospheres pressure for $72 \mathrm{~h}$. After this time, the reaction mixture was filtered through Whatman Microfibre GF/F filter paper and the autoclave rinsed with methanol. The rinses and filtrate were combined and concentrated to dryness under vacuum to yield 7 as a colourless oil $(1.27 \mathrm{~g}, 3.39 \mathrm{mmol}, 99 \%)$. ${ }^{1} \mathrm{H}$ NMR $\left(400 \mathrm{MHz}, \mathrm{CDCl}_{3}\right)$ $\delta=3.48(\mathrm{~m}, 2 \mathrm{H}, 2 \times \mathrm{CH}-\mathrm{O}), 2.35\left(\mathrm{~m}, 2 \mathrm{H}, 1 \times \mathrm{CH}_{2}\right), 1.99(\mathrm{~m}, 2 \mathrm{H}, 2 \times$ $\left.\mathrm{CH}-\mathrm{NH}_{2}\right), 1.26\left(\mathrm{~m}, 2 \mathrm{H}, 1 \times \mathrm{CH}_{2}\right), 0.89\left(\mathrm{~s}, 18 \mathrm{H}, 6 \times \mathrm{CH}_{3}\right), 0.08(\mathrm{~s}, 6 \mathrm{H}$, $\left.2 \times \mathrm{CH}_{3}\right), 0.06\left(\mathrm{~s}, 6 \mathrm{H}, 2 \times \mathrm{CH}_{3}\right) ;{ }^{13} \mathrm{C}$ NMR $\left(100.6 \mathrm{MHz}, \mathrm{CDCl}_{3}\right) \delta=74.5$ 55.2, 41.1, 26.2, 18.2, -3.8, -4.6; FT-IR (neat): $\tilde{V}=2952,2928,2856$, 1578, 1472, 1388, 1360, 1250, 1104, 1065, $1005 \mathrm{~cm}^{-1}$; MS (ESI) $\mathrm{m} / \mathrm{z} \cdot 375[\mathrm{M}+\mathrm{H}]^{+}$.

CC16: To a solution of $(1 R, 2 R, 4 R, 5 R)-4,5$-dimethylcyclohexane-1,2diamine dihydrochloride $(0.58 \mathrm{~g}, 2.70 \mathrm{mmol})$ in methanol $(15 \mathrm{~mL})$ was 
added triethylamine $(0.55 \mathrm{~g}, 5.44 \mathrm{mmol})$ and the resulting solution was stirred for $20 \mathrm{~min}$. After this time, the solution was layered slowly via Pasteur pipette onto a suspension of TFB $(0.28 \mathrm{~g}, 1.73 \mathrm{mmol})$ in $\mathrm{CH}_{2} \mathrm{Cl}_{2}$ $(12 \mathrm{~mL})$. The reaction mixture was sealed and left standing at $\mathrm{rt}$ for $5 \mathrm{~d}$. After this time, the volume of the homogeneous, green reaction mixture was reduced under vacuum $\left(<20^{\circ} \mathrm{C}\right)$ until precipitation was induced. The white precipitate was isolated by vacuum filtration, washed with methano $(2 \times 5 \mathrm{~mL})$ and dried under vacuum to yield CC16 as a powdery white solid (0.44 g, $0.34 \mathrm{mmol}, 79 \%)$. ${ }^{1} \mathrm{H}$ NMR (400 MHz, $\left.\mathrm{CDCl}_{3}\right) \delta=8.16$ (s, $12 \mathrm{H}, 12 \times \mathrm{CH}=\mathrm{N}), 7.89(\mathrm{~s}, 12 \mathrm{H}, 12 \times \mathrm{ArH}), 3.54(\mathrm{~m}, 12 \mathrm{H}, 12 \times \mathrm{CH}-\mathrm{N})$, $2.12\left(\mathrm{~m}, 12 \mathrm{H}, 6 \times \mathrm{CH}_{2}\right), 1.83\left(\mathrm{~m}, 12 \mathrm{H}, 6 \times \mathrm{CH}_{2}\right), 1.30(\mathrm{~m}, 12 \mathrm{H}, 12 \times$ $\left.\mathrm{CH}-\mathrm{CH}_{3}\right), 1.19\left(\mathrm{~d}, 36 \mathrm{H}, 12 \times \mathrm{CH}_{3}\right) ;{ }^{13} \mathrm{C}$ NMR $\left(100.6 \mathrm{MHz}, \mathrm{CDCl}_{3}\right)$ $\delta=159.6,136.0,129.5,69.4,32.8,32.7,19.5 ; \mathrm{FT}-\mathrm{IR}$ (neat): $\tilde{v}=2960$, 2922, 2875, 1647, 1457, 1376, 1156, 1099, 1001, $961 \mathrm{~cm}^{-1}$; MS (MALDITOF, dithranol): $\mathrm{m} / \mathrm{z}: 1286[\mathrm{M}+\mathrm{H}]^{+}$; elemental analysis calcd (\%) for $\mathrm{C}_{84} \mathrm{H}_{108} \mathrm{~N}_{12}$ : C 78.46, H 8.47, N 13.07; found: C 73.62, H 8.33, N 12.17.

CC17: Route 1. To a suspension of $(1 S, 2 S, 4 R, 5 R)-4,5$ diaminocyclohexane-1,2-diol dihydrochloride $(0.40 \mathrm{~g}, 1.83 \mathrm{mmol})$ in methanol $(40 \mathrm{~mL})$ was added triethylamine $(0.37 \mathrm{~g}, 3.65 \mathrm{mmol})$ and the resulting solution was stirred for $20 \mathrm{~min}$. After this time, the solution was layered slowly via Pasteur pipette onto a solution of TFB (0.19 g, 1.17 $\mathrm{mmol})$ in methanol $(40 \mathrm{~mL})$. The reaction mixture was sealed and left standing for $4 \mathrm{~d}$. After this time, both amorphous and crystalline precipitate was observable. The reaction mixture was concentrated to dryness under a nitrogen flow, at which point the crude solid was washed with $\mathrm{CH}_{2} \mathrm{Cl}_{2}$-methanol $(95: 5,2 \times 10 \mathrm{~mL})$, isolated by filtration and then dried under vacuum to yield the crude product as a brown solid $(0.36 \mathrm{~g})$. Separate samples were combined, with the crude product dissolved in DMSO-methanol $(2: 1,24 \mathrm{~mL})$, and the resulting solution was syringe filtered $(0.45 \mu \mathrm{m})$ and purified by preparative HPLC. The productcontaining fractions were concentrated to dryness under vacuum to yield CC17 as a powdery white solid $(0.11 \mathrm{~g}, 0.08 \mathrm{mmol}, 17 \%)$. Route $\mathbf{2}^{[20]}$ With stirring, TBAF (1 $\mathrm{M}$ in THF, $0.90 \mathrm{~mL}, 0.90 \mathrm{mmol}$ ) was added dropwise to a cooled solution of CC19 $(0.10 \mathrm{~g}, 0.04 \mathrm{mmol})$ in THF $(12 \mathrm{~mL})$. After stirring at $\mathrm{rt}$ for $24 \mathrm{~h}$, the reaction mixture was quenched with $1 \mathrm{M} \mathrm{NH}_{4} \mathrm{Cl}(1.5 \mathrm{~mL})$ and the THF was removed under vacuum $\left(<20^{\circ} \mathrm{C}\right)$ to leave a white suspension. This was transferred to a Corning ${ }^{\circledR}$ Spin- $X^{\circledR}$ UF centrifugal concentrator (30K MWCO) and the white precipitate was successively washed with water-acetonitrile $(95: 5,12 \mathrm{~mL})$ and water $(3 \times 12 \mathrm{~mL})$. The collected white solid was suspended in a minimum amount of water and then freeze-dried for $2 \mathrm{~d}$ to yield $\mathbf{C C} 17$ as a powdery white solid (0.03 g, $0.02 \mathrm{mmol}, 61 \%) .{ }^{1} \mathrm{H} \mathrm{NMR} \mathrm{(400} \mathrm{MHz,}$ [D $\left.\left.\mathrm{D}_{6}\right] \mathrm{DMSO}\right) \delta=8.23(\mathrm{~s}, 12 \mathrm{H}, 12 \times \mathrm{CH}=\mathrm{N}), 7.82(\mathrm{~s}, 12 \mathrm{H}, 12 \times \mathrm{ArH}), 4.79$ (br. s, $12 \mathrm{H}, 12 \times \mathrm{CH}-\mathrm{OH}), 3.44(\mathrm{~m}, 24 \mathrm{H}, 12 \times \mathrm{CH}-\mathrm{N}+12 \times \mathrm{CH}-\mathrm{OH})$, $1.68\left(\mathrm{~m}, 24 \mathrm{H}, 12 \times \mathrm{CH}_{2}\right) ;{ }^{13} \mathrm{C} \mathrm{NMR}\left(100.6 \mathrm{MHz},\left[\mathrm{D}_{7}\right] \mathrm{DMF},\right) \delta=160.3$, 137.9, 130.1, 74.3, 73.6, 40.2; FT-IR (neat): $\tilde{v}=3358,2929,2866,1646$, 1449, 1378, 1325, 1160, 1110, 1037, 1007, 919, $696 \mathrm{~cm}^{-1}$; MS (MALDITOF, DCTB): $\mathrm{m} / \mathrm{z}$ : $1310[\mathrm{M+H}]^{+}$; elemental analysis calcd (\%) for $\mathrm{C}_{72} \mathrm{H}_{84} \mathrm{~N}_{12} \mathrm{O}_{12}$ : C 66.04, H 6.47, N 12.84; found: C 59.64, H 6.63, N 11.15.

CC18: A solution of $4(0.25 \mathrm{~g}, 1.06 \mathrm{mmol})$ in $\mathrm{CH}_{2} \mathrm{Cl}_{2}(20 \mathrm{~mL})$ was added slowly via Pasteur pipette onto a solution of TFB $(0.11 \mathrm{~g}, 0.68 \mathrm{mmol})$ and a catalytic amount of TFA in $\mathrm{CH}_{2} \mathrm{Cl}_{2}(20 \mathrm{~mL})$. The reaction mixture was sealed and left standing at rt for $7 \mathrm{~d}$. After this time, a small amount of white precipitate was observable. With stirring, the reaction mixture was diluted with $\mathrm{CH}_{2} \mathrm{Cl}_{2}(40 \mathrm{~mL})$ and quenched with excess sodium hydrogen carbonate. The suspension was filtered under vacuum and the filtrate reduced to a volume of $10 \mathrm{~mL}$ under vacuum $\left(<20^{\circ} \mathrm{C}\right)$. Acetone $(20 \mathrm{~mL})$ was added and the reaction mixture stirred under ice for $20 \mathrm{~min}$ to leave a white turbid solution. This was reduced to a volume of $10 \mathrm{~mL}$ under vacuum $\left(<20^{\circ} \mathrm{C}\right)$ and the precipitate was isolated by vacuum filtration, washed with cold acetone $(2 \times 5 \mathrm{~mL})$ and dried under vacuum to yield CC18 as a powdery white solid $(0.10 \mathrm{~g}, 0.03 \mathrm{mmol}, 32 \%)$. ${ }^{1} \mathrm{H}$ NMR (400 MHz, $\left.\mathrm{CDCl}_{3}\right) \delta=8.28(\mathrm{~s}, 24 \mathrm{H}, 24 \times \mathrm{CH}=\mathrm{N}), 7.80$ (s, $24 \mathrm{H}$,
$24 \times \mathrm{ArH}), 7.38-7.15(\mathrm{~m}, 96 \mathrm{H}, 96 \times \mathrm{ArH}), 4.09(\mathrm{~s}, 24 \mathrm{H}, 24 \times \mathrm{Ar}-\mathrm{CH})$, $3.75(\mathrm{~s}, 24 \mathrm{H}, 24 \times \mathrm{CH}-\mathrm{N}) ;{ }^{13} \mathrm{C} \mathrm{NMR}\left(100.6 \mathrm{MHz}, \mathrm{CDCl}_{3}\right) \delta=161.6$, 142.4, 140.5, 136.9, 129.7, 126.2, 126.1, 125.7, 123.8, 77.4, 53.9; FT-IR (neat): $\tilde{V}=3021,2944,2856,1703,1637,1595,1458,1153,1116,1024$, 965, 882; elemental analysis calcd (\%) for $\mathrm{C}_{264} \mathrm{H}_{192} \mathrm{~N}_{24}$ : C 85.69, H 5.23, N 9.08; found: C 79.64, H 4.91, N 8.17.

CC19: A solution of $7(0.64 \mathrm{~g}, 1.71 \mathrm{mmol})$ in $\mathrm{CH}_{2} \mathrm{Cl}_{2}(30 \mathrm{~mL})$ was added slowly via Pasteur pipette onto a solution of TFB $(0.18 \mathrm{~g}, 1.11 \mathrm{mmol})$ in $\mathrm{CH}_{2} \mathrm{Cl}_{2}(35 \mathrm{~mL})$ and left standing at $\mathrm{rt}$ for $7 \mathrm{~d}$. After this time, a white precipitate was observable. The volume of $\mathrm{CH}_{2} \mathrm{Cl}_{2}$ was reduced by half under vacuum $\left(<20^{\circ} \mathrm{C}\right)$ and the precipitate isolated by vacuum filtration, washed with methanol $(2 \times 10 \mathrm{~mL})$ and dried under vacuum to yield CC18 as a powdery white solid $(0.57 \mathrm{~g}, 0.21 \mathrm{mmol}, 77 \%) .{ }^{1} \mathrm{H}$ NMR (400 $\left.\mathrm{MHz} \mathrm{CDCl}_{3}\right) \delta=8.15(\mathrm{~s}, 12 \mathrm{H}, 12 \times \mathrm{CH}=\mathrm{N}), 7.93(\mathrm{~s}, 12 \mathrm{H}, 12 \times \mathrm{ArH})$, $3.68(\mathrm{~m}, 12 \mathrm{H}, 12 \times \mathrm{CH}-\mathrm{O}), 3.37(\mathrm{~m}, 12 \mathrm{H}, 12 \times \mathrm{CH}-\mathrm{N}), 1.79(\mathrm{~m}, 24 \mathrm{H}, 12$ $\left.\times \mathrm{CH}_{2}\right), 0.87\left(\mathrm{~s}, 108 \mathrm{H}, 36 \times \mathrm{CH}_{3}\right), 0.09\left(\mathrm{~s}, 36 \mathrm{H}, 12 \times \mathrm{CH}_{3}\right), 0.07$ (s, $\left.36 \mathrm{H}, 12 \times \mathrm{CH}_{3}\right) ;{ }^{13} \mathrm{C}$ NMR $\left(100.6 \mathrm{MHz} \mathrm{CDCl}_{3}\right) \delta=159.9,136.5,130.0$, $74.4,72.7,40.3,26.2,18.3,-3.7,-4.6$; FT-IR (neat): $\tilde{v}=2953,2929,2857$, 1648, 1472, 1388, 1251, 1164, 1053, 1006, $964 \mathrm{~cm}^{-1}$; MS (MALDI-TOF, DCTB): $m / z: 2680 \quad[M+H]^{+}$; elemental analysis calcd (\%) for $\mathrm{C}_{144} \mathrm{H}_{252} \mathrm{~N}_{12} \mathrm{O}_{12} \mathrm{Si}_{12}$ : C 64.52, H 9.48, N 6.27; found: C 63.03, H 9.43, N 6.13.

\section{Acknowledgements}

We thank the Engineering and Physical Sciences Research Council (EPSRC) for financial support (EP/H000925/1), Diamond Light Source for access to beamline I19 (MT11231), and Gareth Smith (University of Manchester) for MALDI-TOF MS analysis. We thank the Advanced Light Source, supported by the Director, Office of Science, Office of Basic Energy Sciences, of the U.S. Department of Energy under Contract No. DE-AC02-05CH11231, and Simon J. Teat and Kevin J. Gagnon for their assistance. We acknowledge computational time on ARCHER, funded by the EPSRC (EP/L000202/1). TH and KEJ are Royal Society University Research Fellows.

Keywords: Cage compounds • Microporous materials • Cycloimination $\bullet$ Gas sorption

\section{References}

[1] T. Tozawa, J. T. A. Jones, S. I. Swamy, S. Jiang, D. J. Adams, S. Shakespeare, R. Clowes, D. Bradshaw, T. Hasell, S. Y. Chong, C. Tang, S. Thompson, J. Parker, A. Trewin, J. Bacsa, A. M. Slawin, A. Steiner, A. I. Cooper, Nat. Mater. 2009, 8, 973-978.

[2] a) M. Brutschy, M. W. Schneider, M. Mastalerz, S. R. Waldvogel, Adv. Mater. 2012, 24, 6049-6052; b) J.-H. Zhang, S.-M. Xie, L. Chen, B.-J. Wang, P.-G. He, L.-M. Yuan, Anal. Chem. 2015, 87 7817-7824; c) J.-K. Sun, W.-W. Zhan, T. Akita, Q. Xu, J. Am Chem. Soc. 2015, 137, 7063-7066; d) T. Uemura, R. Nakanishi, S. Mochizuki, S. Kitagawa, M. Mizuno, Angew. Chem. Int. Ed. 2016, 55, 6443-6447.

[3] T. Hasell, S. Y. Chong, K. E. Jelfs, D. J. Adams, A. I. Cooper, J. Am. Chem. Soc. 2012, 134, 588-598.

[4] T. Hasell, M. Schmidtmann, C. A. Stone, M. W. Smith, A. I. Cooper, Chem. Commun. 2012, 48, 4689-4691.

[5] Q. Song, S. Jiang, T. Hasell, M. Liu, S. Sun, A. K. Cheetham E. Sivaniah, A. I. Cooper, Adv. Mater. 2016, 28, 2629-2637.

[6] a) L. Chen, P. S. Reiss, S. Y. Chong, D. Holden, K. E. Jelfs T. Hasell, M. A. Little, A. Kewley, M. E. Briggs, A. Stephenson, K. M. Thomas, J. A. Armstrong, J. Bell, J. Busto, R. Noel, J. Liu, D. M. Strachan, P. K. Thallapally, A. I. Cooper, Nat. Mater. 2014, 
13, 954-960; b) A. Kewley, A. Stephenson, L. Chen, M. E. Briggs, T. Hasell, A. I. Cooper, Chem. Mater. 2015, 27, 3207-3210; c) T. Hasell, M. Miklitz, A. Stephenson, M. A. Little, S. Y. Chong, R. Clowes, L. Chen, D. Holden, G. A. Tribello, K. E. Jelfs, A. I. Cooper, J. Am. Chem. Soc. 2016, 138, 1653-1659.

[7] G. Zhang, O. Presly, F. White, I. M. Oppel, M. Mastalerz, Angew. Chem. Int. Ed. 2014, 53, 1516-1520.

[8] K. Ono, K. Johmoto, N. Yasuda, H. Uekusa, S. Fujii, M. Kiguchi, N. Iwasawa, J. Am. Chem. Soc. 2015, 137, 7015-7018.

[9] A. Avellaneda, P. Valente, A. Burgun, J. D. Evans, A. W. MarkwellHeys, D. Rankine, D. J. Nielsen, M. R. Hill, C. J. Sumby, C. J. Doonan, Angew. Chem. 2013, 52, 3746-3749.

[10] A. G. Slater, A. I. Cooper, Science 2015, 348

[11] a) M. J. Bojdys, M. E. Briggs, J. T. A. Jones, D. J. Adams, S. Y Chong, M. Schmidtmann, A. I. Cooper, J. Am. Chem. Soc. 2011 133, 16566-16571; b) T. Hasell, J. L. Culshaw, S. Y. Chong, M. Schmidtmann, M. A. Little, K. E. Jelfs, E. O. Pyzer-Knapp H. Shepherd, D. J. Adams, G. M. Day, A. I. Cooper, J. Am. Chem. Soc. 2014, 136, 1438-1448.

[12] a) N. Giri, C. E. Davidson, G. Melaugh, M. G. Del Pópolo, J. T. A Jones, T. Hasell, A. I. Cooper, P. N. Horton, M. B. Hursthouse S. L. James, Chem. Sci. 2012, 3, 2153; b) G. Melaugh, N. Giri, C. E. Davidson, S. L. James, M. G. Del Pópolo, Phys. Chem Chem. Phys. 2014, 16, 9422-9431; c) N. Giri, M. G. Del Pópolo, G. Melaugh, R. L. Greenaway, K. Rätzke, T. Koschine, L. Pison, M. F. C. Gomes, A. I. Cooper, S. L. James, Nature 2015, 527, 216 220.

[13] a) S. I. Swamy, J. Bacsa, J. T. A. Jones, K. C. Stylianou, A. Steiner L. K. Ritchie, T. Hasell, J. A. Gould, A. Laybourn, Y. Z. Khimyak, D. J. Adams, M. J. Rosseinsky, A. I. Cooper, J. Am. Chem. Soc. 2010, 132, 12773-12775; b) Y. Jin, B. A. Voss, R. McCaffrey, C. T. Baggett, R. D. Noble, W. Zhang, Chem. Sci. 2012, 3, 874; C) M. Kitchin, K. Konstas, C. J. Sumby, M. L. Czyz, P. Valente, M. R. Hill, A. Polyzos, C. J. Doonan, Chem. Commun. 2015, 51 14231-14234.

[14] M. Liu, M. A. Little, K. E. Jelfs, J. T. A. Jones, M. Schmidtmann, S. Y. Chong, T. Hasell, A. I. Cooper, J. Am. Chem. Soc. 2014, 136 7583-7586.

[15] M. W. Schneider, I. M. Oppel, A. Griffin, M. Mastalerz, Angew. Chem. 2013, 52, 3611-3615.

[16] a) F. Grepioni, D. Savoia, J. Org. Chem. 1997, 62, 4180-4182 b) F. Grepioni, S. Grilli, G. Martelli, D. Savoia, J. Org. Chem. 1999
64, 3679-3683; c) Y. N. Belokon, J. Fuentes, M. North, J. W. Steed, Tetrahedron 2004, 60, 3191-3204.

[17] a) G. Alvaro, S. Grilli, G. Martelli, D. Savoia, Eur. J. Org. Chem 1999, 1999, 1523-1526; b) S. Grilli, G. Martelli, D. Savoia C. Zazzetta, Adv. Synth. Catal. 2002, 344, 1068-1072 c) D. Savoia, D. Balestri, S. Grilli, M. Monari, Eur. J. Org. Chem. 2014, 2014, 1907-1914.

[18] E. J. Corey, A. Venkateswarlu, J. Am. Chem. Soc. 1972, 94, 61906191

[19] V. Suresh, J. J. P. Selvam, K. Rajesh, V. Shekhar, D. C. Babu Y. Venkateswarlu, Synthesis 2010, 2010, 1763-1765

[20] S. Hanessian, R. Margarita, A. Hall, S. Johnstone, M. Tremblay, L. Parlanti, J. Am. Chem. Soc. 2002, 124, 13342-13343.

[21] a) D. Xu, R. Warmuth, J. Am. Chem. Soc. 2008, 130, 7520-7521; b) K. E. Jelfs, X. Wu, M. Schmidtmann, J. T. A. Jones, J. E. Warren, D. J. Adams, A. I. Cooper, Angew. Chem. 2011, 50 10653-10656; c) P. Skowronek, B. Warzajtis, U. Rychlewska, J. Gawronski, Chem. Commun. 2013, 49, 2524-2526.

[22] M. W. Schneider, I. M. Oppel, H. Ott, L. G. Lechner, H. J. Hauswald, R. Stoll, M. Mastalerz, Chem. Eur. J. 2012, 18, 836-847. H. Nowell, S. A. Barnett, K. E. Christensen, S. J. Teat, D. R. Allan,

[23] H. Nowell, S. A. Barnett, K. E. Christensen, S. J. Teat, D. R. Allan,
J. Synchrotron Rad. 2012, 19, 435-441.
[24] Göttingen, Germany 2008 b) L. Krause, R. Herbst-Irmer, G. M. Sheldrick, D. Stalke, J. Appl. Cryst. 2015, 48, 3-10.

G. Sheldrick, Acta Cryst. Sect. D 2010, 66, 479-485

G. Sheldrick, Acta Cryst. Sect. A 2015, 71, 3-8

G. Sheldrick, Acta Cryst. Sect. A 2008, 64, 112-122.

G. Sheldrick, Acta Cryst. Sect. C 2015, 71, 3-8.

O. V. Dolomanov, L. J. Bourhis, R. J. Gildea, J. A. K. Howard, H. Puschmann, J. Appl. Cryst. 2009, 42, 339-341.

[30] E. Harder, W. Damm, J. Maple, C. Wu, M. Reboul, J. Y. Xiang L. Wang, D. Lupyan, M. K. Dahlgren, J. L. Knight, J. W. Kaus, D. S. Cerutti, G. Krilov, W. L. Jorgensen, R. Abel, R. A. Friesner, J. Chem. Theory Comput. 2016, 12, 281-296.

[31] J. VandeVondele, M. Krack, F. Mohamed, M. Parrinello, T. Chassaing, J. Hutter, Computer Physics Communications 2005 167, 103-128.

[32] J. VandeVondele, J. Hutter, J. Chem. Phys. 2007, 127, 114105

[33] S. Grimme, J. Antony, S. Ehrlich, H. Krieg, J. Chem. Phys. 2010 132,154104 
Layout 1:

\section{FULL PAPER}

Cage Decorating: Imine porous organic cages that possess a range of chemical functionalities on the cage periphery were prepared. The use of different functionalized diamine precursors led to cage compounds of different sizes and porosities, including one cage with the potential for further post-synthetic modification.

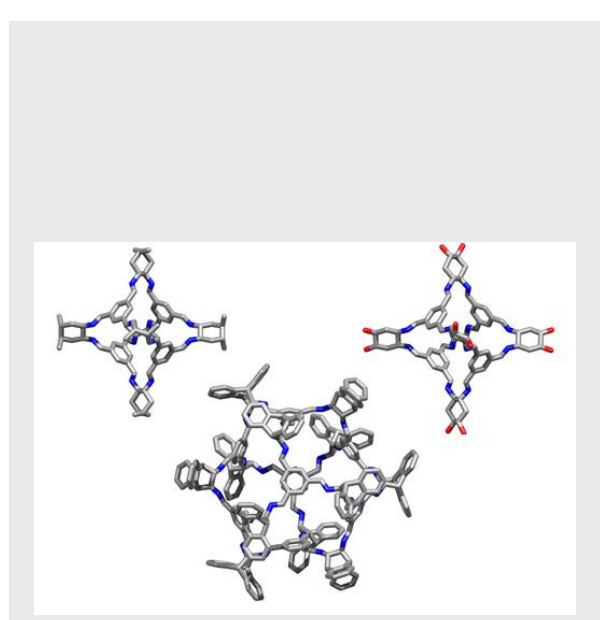

Paul S. Reiss, Marc A. Little, V. Santolini, Sam Y. Chong, Tom Hasell, Kim E. Jelfs, Michael E. Briggs* and Andrew I. Cooper*

Page No. - Page No.

Periphery-Functionalized Porous Organic Cages

Layout 2:

\section{FULL PAPER}

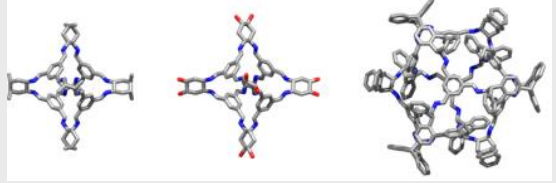

Cage Decorating: Imine porous organic cages that possess a range of chemical functionalities on the cage periphery were prepared. The use of different functionalized diamine precursors led to cage compounds of different sizes and porosities, including one cages with the potential for further post-synthetic modification.
Paul S. Reiss, Marc A. Little, V. Santolini, Sam Y. Chong, Tom Hasell, Kim E. Jelfs, Michael E. Briggs* ${ }^{*}$ and Andrew I. Cooper*

Page No. - Page No.

Periphery-Functionalized Porous Organic Cages 